\title{
A comparison of well-being of carers of people with dementia and their ability to manage before and during the COVID-19 pandemic: findings from the IDEAL study
}

\section{Laura D Gamble ( $\sim$ laura.gamble@newcastle.ac.uk)}

Population Health Sciences Institute, Faculty of Medical Sciences, Newcastle University, UK https://orcid.org/0000-0001-8496-9705

\section{Sophie Parker}

REACH: College of Medicine and Health, University of Exeter, Exeter, UK https://orcid.org/0000-00034878-9859

\section{Catherine Quinn}

Centre for Applied Dementia Studies, Bradford University, UK https://orcid.org/0000-0001-9553-853X

\section{Holly Q Bennett}

Population Health Sciences Institute, Faculty of Medical Sciences, Newcastle University, UK https://orcid.org/0000-0002-4085-8023

\section{Anthony Martyr}

REACH: College of Medicine and Health, University of Exeter, Exeter, UK https://orcid.org/0000-00021702-8902

\section{Serena Sabatini}

REACH: College of Medicine and Health, University of Exeter, Exeter, UK https://orcid.org/0000-00023618-6949

\section{Claire Pentecost}

REACH: College of Medicine and Health, University of Exeter, Exeter, UK https://orcid.org/0000-00032048-5538

\section{Rachel Collins}

REACH: College of Medicine and Health, University of Exeter, Exeter, UK https://orcid.org/0000-00023405-7932

\section{Eleanor Dawson}

REACH: College of Medicine and Health, University of Exeter, Exeter, UK https://orcid.org/0000-00024883-7307

\section{Anna Hunt}

REACH: College of Medicine and Health, University of Exeter, Exeter, UK https://orcid.org/0000-00017523-1792

\section{Louise Allan}


REACH: College of Medicine and Health, University of Exeter, Exeter, UK https://orcid.org/0000-00028912-4901

\section{Alistair Burns}

Institute of Brain, Behaviour and Mental Health, University of Manchester, UK https://orcid.org/00000002-9837-0645

\section{Rachael Litherland}

Innovations in Dementia CIC, Exeter, UK

\section{Christina Victor}

College of Health, Medicine and Life Sciences, Brunel University London, UK https://orcid.org/00000002-4213-3974

\section{Fiona E Matthews}

Population Health Sciences Institute, Faculty of Medical Sciences, Newcastle University, UK https://orcid.org/0000-0002-1728-2388

\section{Linda Clare}

REACH: College of Medicine and Health, University of Exeter, Exeter, UK; 7 NIHR Applied Research Collaboration South-West Peninsula, UK https://orcid.org/0000-0003-3989-5318

\section{Research Article}

Keywords: Quality of life, well-being, coping, competence, role captivity, Alzheimer's Disease

Posted Date: March 7th, 2022

DOI: https://doi.org/10.21203/rs.3.rs-1418603/v1

License: (a) (i) This work is licensed under a Creative Commons Attribution 4.0 International License. Read Full License 


\section{Abstract \\ Background}

Lockdown and social restriction measures imposed to curb the spread of COVID-19 in the United Kingdom impacted on carers of people with dementia, limiting their access to support services and increasing perceived burden of caring. Few studies have compared data collected during the pandemic and data collected before the pandemic to examine the effect of these changes.

\section{Objective}

To explore whether the COVID-19 pandemic affected the well-being of carers of people with dementia, and their ability to cope with their caring responsibilities.

\section{Methods}

Carers of people with dementia living in the community who were enrolled in the IDEAL programme were split into two groups matched on demographic characteristics: the 'pre-pandemic group' $(n=312)$, assessed at two time points prior to the pandemic, and the 'pandemic group', assessed prior to and several months into the pandemic $(n=156)$. Self-report measures of carer well-being, quality of life, coping, perceived competence and role captivity were completed.

\section{Results}

Compared to the pre-pandemic group, those in the pandemic group appeared to cope better and had more stable self-rated competency and role captivity. They did not differ in terms of well-being or quality of life.

\section{Conclusion}

Despite reports of negative impacts on carers early in the pandemic, our findings suggest the pandemic had little negative longer-term impact on carers of people with dementia, and in fact they appeared to have a more positive attitude towards coping several months into the pandemic.

\section{Introduction}

The COVID-19 pandemic has had a detrimental effect on people with dementia and their carers [1, 2]. From a health perspective, people with dementia have a high risk of contracting COVID-19 and, if infected, have a high risk of disease-related morbidity and mortality [3-5]. To protect those most vulnerable, governments put in place restrictions such as social distancing, isolation, and limitations on household 
mixing to help curb the spread of the virus [6, 7]. Whilst important, this disrupted the lives of people with dementia and their carers, with many carers reporting a faster than expected cognitive decline in the person with dementia following the prolonged social restrictions [8-10]. As a result of the pandemic and associated restrictions, carers have been faced with new and largely unfamiliar challenges including a reduction in access to health and social care, increased caring responsibility, lack of respite, changes in daily routines and activities of the person with dementia, and management of worsening behavioural and psychological symptoms of dementia [2, 11-19].

There is emerging evidence of the impact of the COVID-19 pandemic on the health and well-being of carers. At the start of the pandemic, many carers described increased uncertainty, worry about adapting to the 'new normal' and loss of control [11]. Others experienced difficulties coping with their daily living activities [14] and approximately $90 \%$ of carers reported at least one symptom of stress [20]. One study reported that carers described feelings of being trapped in their situation, having no choice but to take on all the responsibility for care [21]. While these studies clearly demonstrate the initial challenges some carers faced in navigating the pandemic, they do not explore the longer-term effects on health and wellbeing. Additionally, many studies utilised retrospective accounts, thus relying upon the accuracy of these accounts and carers' perceptions of change since the pandemic $[11,14,20,22,23]$. This recall may be influenced by current events, prior psychological condition, and the timing of data collection in relation to the pandemic. Consequently, there are contradictory findings with some carers reporting no significant changes in their anxiety and well-being throughout the pandemic [22] and others reporting an increase in carers' stress, burden, anxiety, sadness, and fear [16, 23, 24].

Few studies have investigated the impact on carers both before and during the pandemic, and those that have done so report equivocal findings. A study that collected data before and during lockdown found that carers reported an increase in carer burden and a decline in their well-being [25]. Meanwhile, other studies found no significant changes in carers' anxiety, well-being, quality of life, or distress [26, 27]. Such discrepancies may be explained in part by the timing of these studies and carers learning to adapt and becoming better-positioned or more equipped to cope with the unfolding situation. For example, although carers in one study reported an increase in stress, anxiety, and depression following a lockdown period, this had started to decrease after two months [28]. Whilst these studies begin to explore the longer-term effects of the pandemic on carers, they still only cover the first few months of the pandemic and do not control for the normal progression of dementia as a cause of increasing burden rather than the pandemic.

The present study therefore aims to further understand the longer-term impact of COVID-19 on carers of people with dementia by comparing changes in well-being and coping across two groups: the 'prepandemic group' - a matched comparison group assessed at two time points prior to the pandemic, and the 'pandemic group' - assessed prior to and during the pandemic. We hypothesised that carers in the pandemic group were more likely to report a reduction in their well-being, quality of life, and ability to cope compared to their matched counterparts pre-pandemic. We expected that carers would feel more trapped 
in their caregiving role, and feel less competent following the COVID-19 restrictions, than carers whose data were collected during two time-points prior to the pandemic.

\section{Materials And Methods}

\section{IDEAL}

The Improving the experience of Dementia and Enhancing Active Life (IDEAL) programme is a longitudinal cohort study comprising of, at baseline, 1537 community-dwelling people with mild-tomoderate dementia (MMSE $\geq 15$ ), and 1277 carers (family members or friends). Carers were recruited alongside the person with dementia to both act as informants and provide information on their own experiences of caregiving. Full details are in the published protocol [29]. Time 1 (T1) data collection took place between 2014 and 2016. 1183 people with dementia and 988 carers returned for Time 2 (T2), which took place approximately 12 months after T1 (2015-2017); 851 people with dementia and 759 carers returned for Time 3 (T3) which took place approximately 12 months after T2 (2016-2018). A further study, IDEAL-2, began in 2018 two years after T3 and was designed to follow-up the IDEAL cohort for three more time-points (Time 4 - Time 6) at yearly intervals [30].

\section{INCLUDE}

The COVID-19 pandemic interrupted IDEAL-2 data collection for Time 4 (2018-2020) and Time 5 (20192021). INCLUDE (Identifying and mitigating the individual and dyadic impact of COVID-19 and life under physical distancing on people with dementia and carers) was funded to look at the impact of COVID-19 on IDEAL participants, and focused on the experiences of people with dementia and their carers from the IDEAL cohort during the pandemic. People with dementia and their carers, living in England or Wales, who had previously participated in the IDEAL cohort were eligible for INCLUDE if they had either participated at the most recent assessment point or indicated willingness to be contacted again at the next assessment point. INCLUDE data were collected in the eight months between September 21st 2020 and April 30th 2021. During this period there were significant and varying national or local restrictions on social contact, travel, retail, and services. In addition, the national vaccination programme began in December 2020. Participants in INCLUDE completed a structured telephone or online interview yielding both quantitative data and responses to open-ended questions. Informed consent was documented for all participants.

IDEAL was approved by Wales Research Ethics Committee 5 (reference 13/WA/0405) and IDEAL-2 by Wales Research Ethics Committee 5 (reference 18/WS/0111) and Scotland A Research Ethics Committee (reference 18/SS/0037). INCLUDE was approved as an amendment to IDEAL-2 for England and Wales (18/WS/0111 AM12). IDEAL and IDEAL-2 are registered with the UK Clinical Research Network (UKCRN), numbers 16593 and 37955.

\section{Participants and Design}


This study uses quantitative data from IDEAL and INCLUDE and focusses on carers of people with dementia that live in the community. To compare the impact of COVID-19 restrictions on different wellbeing and coping-related outcomes of carers of people with dementia, two subsamples were identified in the IDEAL and INCLUDE datasets for case-control matching: the pre-pandemic group $(n=312)$ comprising carers who took part in IDEAL T1 and IDEAL T3, but not INCLUDE, and the pandemic group $(n=156)$ comprising carers who were assessed for both IDEAL T3 and INCLUDE. Both the pre-pandemic and pandemic groups incorporated two waves of data; for the pre-pandemic group, wave 1 (w1) refers to IDEAL T1 and wave 2 (w2) refers to IDEAL T3, and for the pandemic group, w1 refers to IDEAL T3 and w2 refers to INCLUDE (see Fig. 1).

$((($ Fig. 1 here $)))$

To obtain the pre-pandemic group, carers were matched 2:1 to carers in the pandemic group based on carer status, carer age group, carer sex, and the diagnosis type and time elapsed since diagnosis of the person with dementia (see Supplementary Fig. 1 for an overview of the matching procedure). Those with missing outcome data were excluded, leaving 481 carers available for matching. For the pre-pandemic group, average time between waves was 24.5 months (range 21-34 months) and for the pandemic group, average time between waves was 39.7 months (range $27-55$ months).

For the pandemic group, of the 156 people included in the study, 77 interviews took place during a period of national lockdown, 48 took place during periods of localised restrictions and 31 took place during the gradual easing of restrictions from 15th March 2021.

\section{Measures}

Single items from standardised measures were used for well-being and quality of life. For well-being the question was 'in the last two weeks, how much of the time have you felt cheerful or in good spirits?' [31], and for quality of life the question was 'how would you rate your quality of life?' [32]. A single question for coping was used: 'do you feel you cope well as a carer?'. A composite score was used for carer competence and role captivity; in each case, three questions generated a total score out of 12 [33, 34]. The details of these questions and response options are found in Supplementary Table 1. Matching variables included carer status (spouse/partner or family/friend), age group $(<65,65-69,70-74,75-79$, 80 + years), sex, diagnosis type (Alzheimer's disease, vascular dementia, mixed Alzheimer's or vascular dementia, frontotemporal dementia, Parkinson's disease dementia, dementia with Lewy bodies or other/unspecified), and length of diagnosis ( $<1$ year, $1-2$ years, $3-5$ years, $6+$ years). The number of hours spent providing care ( $<1$ hour per day, $1-10$ hours per day, or $10+$ hours per day) was included as a covariate.

\section{Statistical methods}

To test whether there were differences in the pre-pandemic and pandemic groups, mixed effect modelling was used, grouping waves within participants, and an interaction between group and wave was modelled. Mixed effect multinomial logistic regression models were used for categorical variables (quality of life, 
well-being, and coping) with the random effects for grouping constrained to be equal for all outcome categories. For continuous outcomes (competence and role captivity) a mixed effect linear regression model was used. Matching variables and carer hours were included in the models as covariates. Including months between waves as either a covariate or an interaction was explored. Analyses were conducted in Stata 16. The grid package available in $\mathrm{R}$ statistical software was used to generate transition plots for categorical outcomes.

\section{Results}

In both the pre-pandemic $(\mathrm{N}=312)$ and pandemic $(\mathrm{N}=156)$ groups, $90 \%$ of carers were spouses or partners, almost two-thirds were women and the average age was approximately 69 years at $\mathrm{w} 1$ (Table 1). Over half of carers were caring for someone with Alzheimer's disease. Over $90 \%$ of the carers lived with the care recipient in both groups (pre-pandemic group, 92.6\%; pandemic group, 90.7\%). During the pandemic the number of carers spending 10 + hours per day caring increased compared to the prepandemic group (pre-pandemic group w1: $34.3 \%$, w2: 53.2\%; pandemic group w1: $37.0 \%$, w2: $66.2 \%$ ). All models were adjusted for number of hours spent providing care. Time between waves was not important when included as either a covariate or interaction in our models, so was excluded from further analyses. 
Table 1

Characteristics of the pre-pandemic and pandemic groups on matching variables

\begin{tabular}{|c|c|c|c|c|c|}
\hline & & \multicolumn{2}{|c|}{ Pre-pandemic } & \multicolumn{2}{|c|}{ Pandemic } \\
\hline & & $\mathbf{N}$ & $\%$ & $\mathbf{N}$ & $\%$ \\
\hline \multirow[t]{2}{*}{ Carer status } & Spouse/partner & 280 & 89.7 & 140 & 89.7 \\
\hline & Family/friend & 32 & 10.3 & 16 & 10.3 \\
\hline \multirow[t]{5}{*}{ Age group } & $<65$ & 73 & 23.4 & 44 & 28.2 \\
\hline & $65-69$ & 78 & 25.0 & 39 & 25.0 \\
\hline & $70-74$ & 73 & 23.4 & 28 & 18.0 \\
\hline & $75-79$ & 42 & 13.5 & 20 & 12.8 \\
\hline & $\geq 80$ & 46 & 14.7 & 25 & 16.0 \\
\hline \multirow[t]{2}{*}{ Sex } & Men & 115 & 36.9 & 58 & 37.2 \\
\hline & Women & 197 & 63.1 & 98 & 62.8 \\
\hline \multirow[t]{7}{*}{ Dementia subtype } & Alzheimer's disease & 178 & 57.1 & 89 & 57.1 \\
\hline & Vascular dementia & 25 & 8.0 & 19 & 12.2 \\
\hline & Mixed (Alzheimer's and vascular) & 67 & 21.5 & 24 & 15.4 \\
\hline & Frontotemporal dementia & 13 & 4.2 & 11 & 7.1 \\
\hline & Parkinson's disease dementia & 11 & 3.5 & 4 & 2.6 \\
\hline & Dementia with Lewy bodies & 10 & 3.2 & 1 & 0.6 \\
\hline & Unspecified/Other & 8 & 2.6 & 8 & 5.1 \\
\hline \multirow[t]{5}{*}{ Length of time since diagnosis } & $<1$ year & 129 & 43.4 & 0 & 0.0 \\
\hline & $1-2$ years & 127 & 42.8 & 74 & 49.3 \\
\hline & $3-5$ years & 37 & 12.5 & 61 & 40.7 \\
\hline & $\geq 6$ years & 4 & 1.3 & 15 & 10.0 \\
\hline & Missing & 16 & & 6 & \\
\hline
\end{tabular}

(((Table 1 here) $))$

\section{Quality of life}

In the pre-pandemic group, $73 \%$ reported high (good or very good) quality of life at w1 compared to $59 \%$ at w2, while $75 \%$ of carers in the pandemic group reported high quality of life at w 1 compared to $62 \%$ by 
w2 (Table 2). The proportions in each class, and how they change between w1 and w2, are shown in transition plots in Fig. 2A. For both pre-pandemic and pandemic groups, fewer carers report quality of life being good or very good at w2, with a large number of carers transitioning from good to neither poor nor good. In the pandemic group, there were more carers moving from good to very good than in the prepandemic group. As shown in Table 3, there is little evidence of a difference between pre-pandemic and pandemic groups at $\mathrm{w} 1$. There was evidence that, in the pre-pandemic group, more carers endorsed neither poor nor good or very poorl poor at w2 than at w1. However, there was no evidence of an interaction between group and wave, suggesting that there is no difference in how carers of people with dementia reported their quality of life between the pre-pandemic and pandemic groups. 
Table 2

Outcomes at wave 1 and wave 2 in the pre-pandemic and pandemic groups

Pre-pandemic

Wave 1

N $\quad$ \%

Quality of life

Very poor

Poor

Neither poor nor good

Good

Very good

Missing

Well-being

At no time

Some of the time

Less than half the $\quad 41$

time

More than half the 93

time

Most of the time

All the time

Missing

3

$1.0 \quad 1$

$9.6 \quad 42$

13.156

$29.8 \quad 90$

$28.9 \quad 43$

$34.9 \quad 68$

$4.5 \quad 8$

$4.2 \quad 14$

13

$-$
Wave 2

$\% \quad \mathbf{N}$

$\begin{array}{ll}7.4 & 7\end{array}$

$32.4 \quad 31$

$46.8 \quad 82$

$12.2 \quad 32$

4

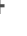

1.30

Pandemic

Wave 1

$\begin{array}{llll}\mathbf{N} & \% & \mathbf{N} & \%\end{array}$

Wave 2

$\%$ 


\begin{tabular}{|c|c|c|c|c|c|c|c|c|}
\hline \multirow[b]{2}{*}{$1-10$ hours } & \multicolumn{4}{|c|}{ Pre-pandemic } & \multicolumn{4}{|c|}{ Pandemic } \\
\hline & 128 & 34.4 & 115 & 37.1 & 67 & 43.5 & 37 & 24.0 \\
\hline $10+$ hours & 106 & 34.3 & 165 & 53.2 & 57 & 37.0 & 102 & 66.2 \\
\hline \multirow[t]{2}{*}{ Missing } & 3 & & 2 & & 2 & & 2 & \\
\hline & $\begin{array}{l}\text { Mean } \\
\text { (sd) }\end{array}$ & $\mathbf{N}$ & $\begin{array}{l}\text { Mean } \\
\text { (sd) }\end{array}$ & $\mathbf{N}$ & $\begin{array}{l}\text { Mean } \\
\text { (sd) }\end{array}$ & $\mathbf{N}$ & $\begin{array}{l}\text { Mean } \\
\text { (sd) }\end{array}$ & $\mathbf{N}$ \\
\hline Competence & $9.3(1.6)$ & 312 & $8.9(1.6)$ & 312 & $\begin{array}{l}9.1 \\
(1.5)\end{array}$ & 152 & $\begin{array}{l}9.3 \\
(1.4)\end{array}$ & 153 \\
\hline Role captivity & $5.3(2.0)$ & 312 & $6.3(2.6)$ & 312 & $\begin{array}{l}5.6 \\
(2.5)\end{array}$ & 151 & $\begin{array}{l}6.1 \\
(2.7)\end{array}$ & 154 \\
\hline
\end{tabular}


Table 3

Multilevel modelling to investigate differences in pre-pandemic and pandemic groups

\begin{tabular}{|c|c|c|c|c|c|c|c|}
\hline \multicolumn{2}{|c|}{ Measures } & \multicolumn{2}{|c|}{$\begin{array}{l}\text { Pandemic vs. pre- } \\
\text { pandemic at } \\
\text { Wave } 1\end{array}$} & \multicolumn{2}{|c|}{$\begin{array}{l}\text { Wave } 2 \text { vs. Wave } 1 \\
\text { for pre-pandemic } \\
\text { group }\end{array}$} & \multicolumn{2}{|c|}{$\begin{array}{l}\text { Interaction between } \\
\text { pandemic group and } \\
\text { Wave }\end{array}$} \\
\hline & & OR & $95 \% \mathrm{Cl}$ & OR & $95 \% \mathrm{Cl}$ & OR & $95 \% \mathrm{Cl}$ \\
\hline \multirow[t]{4}{*}{$\begin{array}{l}\text { Quality } \\
\text { of life }\end{array}$} & Very poor/poor & 1.38 & $\begin{array}{l}0.37- \\
5.22\end{array}$ & 3.45 & $1.43-8.31$ & 0.90 & $0.22-3.72$ \\
\hline & Neither poor nor good & 0.60 & $\begin{array}{l}0.30- \\
1.19\end{array}$ & 1.54 & $0.99-2.40$ & 0.98 & $0.45-2.15$ \\
\hline & Good & Ref & & Ref & & Ref & \\
\hline & Very good & 1.15 & $\begin{array}{l}0.56- \\
2.36\end{array}$ & 0.97 & $0.56-1.67$ & 1.32 & $0.55-3.15$ \\
\hline \multirow[t]{3}{*}{$\begin{array}{l}\text { Well- } \\
\text { being }\end{array}$} & $\begin{array}{l}\text { At no time/some of } \\
\text { the time }\end{array}$ & 0.49 & $\begin{array}{l}0.16- \\
1.47\end{array}$ & 1.43 & $0.77-2.66$ & 1.83 & $0.57-5.89$ \\
\hline & $\begin{array}{l}\text { Less than half the } \\
\text { time/more than half } \\
\text { the time }\end{array}$ & 0.81 & $\begin{array}{l}0.39- \\
1.68\end{array}$ & 1.30 & $0.83-2.05$ & 0.67 & $0.32-1.44$ \\
\hline & $\begin{array}{l}\text { Most of the time/all } \\
\text { of the time }\end{array}$ & Ref & & Ref & & Ref & \\
\hline \multirow[t]{4}{*}{ Coping } & Never/sometimes & 1.20 & $\begin{array}{l}0.66- \\
2.15\end{array}$ & 1.74 & $1.14-2.65$ & 0.56 & $0.27-1.15$ \\
\hline & Often & Ref & & Ref & & Ref & \\
\hline & Always & 0.71 & $\begin{array}{l}0.38- \\
1.33\end{array}$ & 0.61 & $0.38-0.97$ & 3.10 & $1.43-6.74$ \\
\hline & & Est & $95 \% \mathrm{Cl}$ & Est & $95 \% \mathrm{Cl}$ & Est & $95 \% \mathrm{Cl}$ \\
\hline \multicolumn{2}{|c|}{ Competence } & 0.00 & $\begin{array}{l}-0.34- \\
0.34\end{array}$ & -0.30 & $\begin{array}{l}-0.48- \\
-0.13\end{array}$ & 0.44 & $0.14-0.74$ \\
\hline \multicolumn{2}{|c|}{ Role captivity } & 0.06 & $\begin{array}{l}-0.46- \\
0.57\end{array}$ & 0.73 & $0.51-0.95$ & -0.54 & $-0.92--0.17$ \\
\hline
\end{tabular}

(((Tables 2 and 3 here $)))$

(((Fig. 2 here) $))$

\section{Well-being}

At w1, 47\% in the pre-pandemic group endorsed high (most of the time or all of the time) well-being, and this decreased to $39 \%$ at w2. In the pandemic group, $50 \%$ at w1 and $47 \%$ at w2 endorsed high well-being (Table 2). As shown in the transition plots (Fig. 2B), fewer carers at w2 endorsed high well-being for both 
pre-pandemic and pandemic groups, and there were no obvious differences in transitions between categories for the two groups. This was supported in the regression model. There was little evidence of a difference between the two groups at w1, and there was limited evidence of an increase in the number of carers endorsing lower (at no time/ some of the time) well-being compared to high (most of the time/ all of the time) well-being for the pre-pandemic group between w1 and w2. There was no evidence of an interaction between group and wave, suggesting no difference in change in perceived well-being in the pre-pandemic compared to the pandemic group.

\section{Coping}

Half of the carers stated they often coped well in both pre-pandemic and pandemic groups, and this remained stable between w1 and w2. However, as shown in the transition plot in Fig. 2C, more carers in the pandemic group transitioned from often to always, and from sometimes to often, compared to the pre-pandemic group. This indicates that carers in the pandemic group may have felt they were coping better compared to the pre-pandemic group. As shown in the regression analysis in Table 3, there was little evidence of a difference at $\mathrm{w} 1$ between pre-pandemic and pandemic groups. There was evidence that for the pre-pandemic group, more carers endorsed never/ sometimes and fewer carers endorsed always at w2 compared to w1. There was a strong interaction between group and wave suggesting that more carers in the pandemic group endorsed always relative to often compared to those in the prepandemic group, and there was some evidence that they were less likely to endorse never/ sometimes in the pandemic group compared to the pre-pandemic group. These findings suggest that carers felt they coped better during the pandemic.

\section{Competence}

As shown in Table 2 and Fig. 2D, the mean competence score was similar across both waves for prepandemic and pandemic groups and so any differences found are small. The scores for pre-pandemic and pandemic groups were similar at baseline with a slight decrease in competence between w1 and w2 in the pre-pandemic group (Table 3). There was an interaction effect indicating less of a decrease in competence in the pandemic group, meaning the competence score in the pandemic group is more stable across the two waves compared to the pre-pandemic group.

\section{Role captivity}

As shown in Table 2 and Fig. 2E, the mean role captivity score increased slightly between w1 and w2 for pre-pandemic and pandemic groups but again differences were relatively small. As shown in Table 3 , there was no difference between pandemic and pre-pandemic groups at w1 with an increase in role captivity score between w1 and w2 for the pre-pandemic group. There was an interaction effect, suggesting that the role captivity score, whilst still increasing, increased to a lesser extent for the pandemic group when compared to the pre-pandemic group. This suggests that carers felt less trapped in their role as a carer during the pandemic than they did pre-pandemic.

\section{Discussion}


To help counter the spread of COVID-19, since March 2020 there have been three national lockdowns in England and Wales, as well as local lockdowns with varying restrictions on social activities in different areas. Here, we followed up on carers from the IDEAL cohort several months into the pandemic, and investigated whether their experience of living through the pandemic and the associated social restrictions affected their well-being, as well as their beliefs about how they managed their caring responsibilities. We used longitudinal data to determine whether the changes in response over time were different during the pandemic compared to before the pandemic, allowing us to distinguish whether any change was due to the COVID-19 pandemic itself or attributable to other possible causes, such as higher levels of carer burden as dementia progressed. Contrary to our hypotheses, we found no effect of the COVID-19 pandemic on either quality of life or well-being of the carers and, interestingly, we found that the carers responded more positively to questions asking about their abilities to cope, their competence, and their feelings of being trapped in their roles compared to how they responded before the pandemic. This suggests that several months after the initial lockdown, the impact of the pandemic did not negatively affect the carers of people with dementia.

Most studies have considered the early stage of the pandemic when there were the greatest restrictions and older people or those with medical conditions were advised to stay at home and shield as much as possible. A number of studies have found that the restrictions and social isolation measures associated with the COVID-19 pandemic negatively impacted on perceived cognition of the person with dementia, increased the severity of neuropsychiatric symptoms, and led to perceived functional decline and decreased independence $[9,25,35]$. Several studies found that carers experienced a higher level of stress or worsening well-being, and increased burden and exhaustion as a result of reduced access to formal care services and respite care, or due to anxiety about the person with dementia catching COVID-19 and refusing support to reduce the risk $[9,11,12,17,22,25,36,37]$. The primary carer, often a spouse, spent more hours caring and had additional responsibilities, particularly when caring for someone with severe dementia [22]. Alzheimer's Society reported a strong negative emotional impact of the pandemic on the mental health outcomes of carers and strained relationships between the carer and person with dementia [37]. Other studies reported greater anxiety, depression, irritability, and helplessness of the carer [17] and high stress and burden, and low quality of life [38] but had no pre-pandemic controls. Another study reported that even before the pandemic, spousal carers found responsibilities overwhelming, and as a result of declining help to reduce risk, felt more trapped and had more conflicts with their partner [21].

However, other studies found less of a negative impact of the pandemic. A qualitative study reported some negative consequences of lockdown on carer well-being, but some carers reported no impact because they continued to engage in meaningful or valued activities, or because they already led a restricted lifestyle before the pandemic [16]. Qualitative interviews of 11 carers from the IDEAL cohort during the initial lockdown, with follow-up in July 2020 when restrictions were easing, found that some carers were coping well and this corresponded with good health, strong relationships and community support [39]. Several studies found that carers reported a strengthened relationship and deeper connections with the care recipient due to spending more time together $[1,16,40]$. In a qualitative study focusing on positive aspects of caring during COVID-19, carers also reported finding a greater connection 
with their values and what was important in their lives, such as the act of caregiving and the way they viewed themselves [40]. Several carers reported gratitude for their experience, which enabled them to develop close relationships with not only the care recipient, but other family members and paid carers, which they wanted to continue. They reported a strengthening of commitment to the person with dementia, and recognised the importance of asking for and accepting help with looking after themselves in an ongoing way and of seeking opportunities to connect with others in the same situation [40]. Some studies found no changes in carer-reported neuropsychiatric symptoms of the person with dementia and no difference in carer stress in the first couple of months of lockdown [27], whereas another study reported worsening neuropsychiatric symptoms but no change in carer well-being [26]. Therefore, the findings from the evidence-base present a mixed picture on the impact of the pandemic on carers.

In our study, more carers reported poorer quality of life at wave 2 compared to wave 1 in both prepandemic and pandemic groups, suggesting a decline in quality of life over time. However, the decline was similar for those in the pandemic group compared to those in the pre-pandemic group. In addition, well-being was stable across time for both groups. Our findings therefore suggest the COVID-19 pandemic had little impact on the well-being of the carer. Almost all of the studies to date were conducted in the first few months of the pandemic, whereas ours was conducted from 8 months onwards, reflecting a longer-term impact of the pandemic on the carer. One study did find increased stress, anxiety, and depression in the carers at the beginning of lockdown which improved after 2 months [28] and another study found that, coinciding with a drop in social support and particularly in day services shortly after lockdown measures were introduced, an upward trend emerged for carers receiving support over three time points (April/May 2020, followed up at 6 weeks and 12 weeks) which corresponded with a decrease in depression, anxiety, and an increase in quality of life [22]. Whilst timing of studies is the most likely explanation for discrepant findings, most studies also did not have appropriate pre-pandemic control groups or did not compare carer measures to pre-pandemic levels at all. To our knowledge, no other study has compared changes during the pandemic to the change in a similar time frame under normal circumstances in the way that ours did. Our findings for quality of life and well-being suggest the changes experienced by carers during the pandemic are parallel to those experienced by carers with similar demographic characteristics under normal circumstances. In addition, many of the studies relied on how the carer remembered things before the pandemic, which may have been impacted by current emotional state.

As far as we know, this is the first quantitative study to look specifically at carers' feelings of coping, competency and role captivity during the pandemic. Whilst there was a small but positive effect on perceived competency and role captivity, our most striking finding was for coping. Whilst pre-pandemic there was a pattern towards a decrease in coping between wave 1 and wave 2 of data collection, there was an increase in the number of carers endorsing better coping between wave 1 and wave 2 of data collection during the pandemic. A qualitative study reported carers expressing feelings that they were struggling to cope early on in the pandemic [14], but a study conducted later in the pandemic, between June 2020 and March 2021, found that three-quarters of the carers believed they were coping well [23]. 
There are several reasons why carers may have begun to feel more positive several months into the pandemic. It is likely that with the changing circumstances and disruptions to daily routines and the loss of external support, carers struggled at the beginning of the pandemic. After overcoming the initial shock of the pandemic, they may have adapted to new routines and coped with the changes. They may have been feeling more optimistic due to the rollout of the vaccination programme, the easing of restrictions, and reintroduction of support services, although this might be dependent on restrictions at the time of interview. They may have more self-belief, and, as several qualitative studies indicate, where their relationships with the care-recipient was already good and reciprocal their relationship may have strengthened [39]. They may also have responded more positively due to greater negative feelings early on in the pandemic meaning they had a lower starting point than those asked pre-pandemic. Finally, in our study, the majority of carers were spouses so there may have been less of a disruption to normal routines particularly for those who did not previously rely on external support services, which is also evidenced in O'Rourke et al [39].

Our study had a number of limitations. Whilst we matched two pre-pandemic carers to each pandemic carer, more carers in the pandemic group were caring for people for whom more time had elapsed since diagnosis, because most of them had been in IDEAL since T1. Time since diagnosis was adjusted for to help mitigate this limitation. Another limitation is the timing of the waves. Because no one was prepared for the COVID-19 pandemic, we had to use pre-pandemic time points that were closest in terms of time between waves for the pre-pandemic and pandemic groups, but the gap between T3 and INCLUDE (pandemic group) was larger than the gap between T1 and T3 (pre-pandemic group). However, we investigated whether including months between waves as a covariate or an interaction impacted on results and found little difference. Our study was conducted between September 2020 and April 2021. There was significant easing of restrictions over summer 2020 (June to September), a national lockdown in England from November to December 2020, another lockdown between January and March 2021, fluctuations in levels of restrictions at other times, and also the introduction of the vaccination programme in December 2020, all of which may have impacted on how positive carers felt at the time of the interview. In addition, quality of life and well-being are usually measured with composite measures in IDEAL, but for INCLUDE only single-item measures were administered. This was to reduce the burden for both researchers and participants as the interview was conducted over the telephone or online. This may have meant that the measures did not reflect the constructs as effectively. Finally, carers were invited to take part in the study even if the care recipient did not, so the study should encompass those who were caring for someone with more severe dementia. However, those carers who were not coping well may have been less inclined to take part, and so the group who were likely to respond most negatively may have been missed.

Our study suggests that, several months into the pandemic, COVID-19 was not having a negative impact on the well-being of carers, and in fact we found a higher level of beliefs that the carer could manage compared to before the pandemic. This study shows a more positive understanding of how carers managed during the pandemic and suggests that, six to twelve months in, carers were resilient and able to cope with the changes brought about by the pandemic. At this point the pandemic was far from over, 
however, and the impact of living through further stages of the pandemic and the eventual return to normality on both carers and care recipients remains to be determined.

\section{Declarations}

\section{Acknowledgements}

We acknowledge the support of NIHR Dementias and Neurodegeneration Specialty (DeNDRoN) and Health and Care Research Wales with IDEAL cohort recruitment and data collection. We gratefully acknowledge the local principal investigators and researchers involved in participant recruitment and assessment within these networks. We are grateful to the IDEAL study participants for their participation in the IDEAL and INCLUDE studies, to the wider group of IDEAL programme researchers, and to members of the ALWAYs group and the Project Advisory Group for their support.

\section{Conflict of Interest/Disclosure Statement}

The authors have no conflict of interest to report

\section{Funding}

'Identifying and mitigating the individual and dyadic impact of COVID19 and life under physical distancing on people with dementia and carers (INCLUDE)' was funded by the Economic and Social Research Council (ESRC) through grant ES/V004964/1. Investigators: Clare, L., Victor, C., Matthews, F., Quinn, C., Hillman, A., Burns, A., Allan, L., Litherland, R., Martyr, A., Collins, R., \& Pentecost, C. ESRC is part of UK Research and Innovation (UKRI).

'Improving the experience of Dementia and Enhancing Active Life: living well with dementia. The IDEAL study' was funded jointly by the Economic and Social Research Council (ESRC) and the National Institute for Health Research (NIHR) through grant ES/L001853/2. Investigators: L. Clare, I.R. Jones, C. Victor, J.V. Hindle, R.W. Jones, M. Knapp, M. Kopelman, R. Litherland, A. Martyr, F.E. Matthews, R.G. Morris, S.M. Nelis, J.A. Pickett, C. Quinn, J. Rusted, J. Thom. IDEAL data were deposited with the UK data archive in April 2020 and will be available to access from April 2023. Details of how the data can be accessed after that date can be found here: http://reshare.ukdataservice.ac.uk/854293/

'Improving the experience of Dementia and Enhancing Active Life: a longitudinal perspective on living well with dementia. The IDEAL-2 study' is funded by Alzheimer's Society, grant number 348, AS-PR2-16001. Investigators: L. Clare, I.R. Jones, C. Victor, C. Ballard, A. Hillman, J.V. Hindle, J. Hughes, R.W. Jones, M. Knapp, R. Litherland, A. Martyr, F.E. Matthews, R.G. Morris, S.M. Nelis, C. Quinn, J. Rusted. 
L. Clare and L Allan acknowledge support from the NIHR Applied Research Collaboration South-West Peninsula.

The views expressed are those of the author(s) and not necessarily those of the ESRC, UKRI, NIHR, the Department of Health and Social Care, the National Health Service, or Alzheimer's Society. The support of ESRC, NIHR and Alzheimer's Society is gratefully acknowledged.

\section{Author contributions}

Conception and design - LC, AM, CP, RC, LA, AB, RL, CQ, FM, SS, HB, LG.

Analysis and interpretation of data - LG conducted the study analysis and interpreted the data. Analysis was supervised by FEM, and HB assisted with methodology.

Drafting the manuscript - LG, SP and CQ drafted the manuscript

Critical appraisal and review of the manuscript - all

Final approval of the manuscript - all

\section{References}

1. Tuijt R, Frost R, Wilcock J, Robinson L, Manthorpe J, Rait G, Walters K (2021) Life under lockdown and social restrictions - the experiences of people living with dementia and their carers during the COVID-19 pandemic in England. BMC Geriatr 21, 301.

2. Tam MT, Dosso JA, Robillard JM (2021) The impact of a global pandemic on people living with dementia and their care partners: analysis of 417 lived experience reports. J Alzheimers Dis $\mathbf{8 0}, \mathbf{8 6 5 -}$ 875.

3. Wang Q, Davis PB, Gurney ME, Xu R (2021) COVID-19 and dementia: Analyses of risk, disparity, and outcomes from electronic health records in the US. Alzheimers Dement 17, 1297-1306.

4. Numbers K, Brodaty H (2021) The effects of the COVID-19 pandemic on people with dementia. Nat Rev Neurol 17, 69-70.

5. Saragih ID, Saragih IS, Batubara So, Lin CJ (2021) Dementia as a mortality predictor among older adults with COVID-19: A systematic review and meta-analysis of observational study. Geriatr Nurs 42, 1230-1239.

6. Wilder-Smith A, Freedman DO (2020) Isolation, quarantine, social distancing and community containment: pivotal role for old-style public health measures in the novel coronavirus (2019-nCoV) outbreak. J Travel Med 27.

7. Thu TPB, Ngoc PNH, Hai NM, Tuan LA (2020) Effect of the social distancing measures on the spread of COVID-19 in 10 highly infected countries. Sci Total Environ 742, 140430. 
8. Borelli WV, Augustin MC, de Oliveira PBF, Reggiani LC, Bandeira-de-Mello RG, Schumacher-Schuh AF, Chaves MLF, Castilhos RM (2021) Neuropsychiatric symptoms in patients with dementia associated with increased psychological distress in caregivers during the COVID-19 pandemic. J Alzheimers Dis 80, 1705-1712.

9. Canevelli M, Palmieri L, Raparelli V, Lo Noce C, Colaizzo E, Tiple D, Vaianella L, Vanacore N, Brusaferro S, Onder G, Italian National Institute of Health C-MG (2020) Prevalence and clinical correlates of dementia among COVID-19-related deaths in Italy. Alzheimers Dement (Amst) 12, e12114.

10. Rainero I, Bruni AC, Marra C, Cagnin A, Bonanni L, Cupidi C, Lagana V, Rubino E, Vacca A, Di Lorenzo R, Provero P, Isella V, Vanacore N, Agosta F, Appollonio I, Caffarra P, Busse C, Sambati R, Quaranta D, Guglielmi V, Logroscino G, Filippi M, Tedeschi G, Ferrarese C, Group SIC-S (2020) The impact of COVID-19 quarantine on patients with dementia and family caregivers: a nation-wide survey. Front Aging Neurosci 12, 625781.

11. Giebel C, Cannon J, Hanna K, Butchard S, Eley R, Gaughan A, Komuravelli A, Shenton J, Callaghan S, Tetlow H, Limbert S, Whittington R, Rogers C, Rajagopal M, Ward K, Shaw L, Corcoran R, Bennett K, Gabbay M (2021) Impact of COVID-19 related social support service closures on people with dementia and unpaid carers: a qualitative study. Aging Ment Health 25, 1281-1288.

12. Cohen G, Russo MJ, Campos JA, Allegri RF (2020) Living with dementia: increased level of caregiver stress in times of COVID-19. Int Psychogeriatr 32, 1377-1381.

13. Savla J, Roberto KA, Blieszner R, McCann BR, Hoyt E, Knight AL (2021) Dementia caregiving during the "Stay-at-Home" phase of COVID-19 pandemic. J Gerontol B Psychol Sci Soc Sci 76, e241-e245.

14. Roach P, Zwiers A, Cox E, Fischer K, Charlton A, Josephson CB, Patten SB, Seitz D, Ismail Z, Smith EE (2021) Understanding the impact of the COVID-19 pandemic on well-being and virtual care for people living with dementia and care partners living in the community. Dementia 20, 2007-2023.

15. Hanna K, Giebel C, Tetlow H, Ward K, Shenton J, Cannon J, Komuravelli A, Gaughan A, Eley R, Rogers C, Rajagopal M, Limbert S, Callaghan S, Whittington R, Butchard S, Shaw L, Gabbay M (2021) Emotional and mental wellbeing following COVID-19 public health measures on people living with dementia and carers. J Geriatr Psychiatry Neurol, 891988721996816.

16. Sriram V, Jenkinson C, Peters M (2021) Impact of COVID-19 restrictions on carers of persons with dementia in the UK: a qualitative study. Age Ageing 50, 1876-1885.

17. Cagnin A, Di Lorenzo R, Marra C, Bonanni L, Cupidi C, Lagana V, Rubino E, Vacca A, Provero P, Isella V, Vanacore N, Agosta F, Appollonio I, Caffarra P, Pettenuzzo I, Sambati R, Quaranta D, Guglielmi V, Logroscino G, Filippi M, Tedeschi G, Ferrarese C, Rainero I, Bruni AC, Group SIC-S (2020) Behavioral and psychological effects of Coronavirus Disease-19 quarantine in patients with dementia. Front Psychiatry 11, 578015.

18. Boutoleau-Bretonniere C, Pouclet-Courtemanche H, Gillet A, Bernard A, Deruet AL, Gouraud I, Lamy E, Mazoue A, Rocher L, Bretonniere C, El Haj M (2020) Impact of confinement on the burden of 
caregivers of patients with the behavioral variant of frontotemporal dementia and Alzheimer disease during the COVID-19 crisis in France. Dement Geriatr Cogn Dis Extra 10, 127-134.

19. Vaitheswaran S, Lakshminarayanan M, Ramanujam V, Sargunan S, Venkatesan S (2020) Experiences and needs of caregivers of persons with dementia in India during the COVID-19 pandemic-a qualitative study. Am J Geriatr Psychiatry 28, 1185-1194.

20. Zucca M, Isella V, Lorenzo RD, Marra C, Cagnin A, Cupidi C, Bonanni L, Lagana V, Rubino E, Vanacore N, Agosta F, Caffarra P, Sambati R, Quaranta D, Guglielmi V, Appollonio IM, Logroscino G, Filippi M, Tedeschi G, Ferrarese C, Rainero I, Bruni AC, Group SIC-S (2021) Being the family caregiver of a patient with dementia during the coronavirus disease 2019 lockdown. Front Aging Neurosci 13, 653533.

21. Hammar L, Johansson M, Dhalberg L, McKee KJ, Summer-Meranius M (2021) Exhausted and trapped in isolation. Caring for a spouse with dementia during the Covid-19 pandemic. Innov Aging 5, 800-801.

22. Giebel C, Pulford D, Cooper C, Lord K, Shenton J, Cannon J, Shaw L, Tetlow H, Limbert S, Callaghan S, Whittington R, Rogers C, Komuravelli A, Rajagopal M, Eley R, Downs M, Reilly S, Ward K, Gaughan A, Butchard S, Beresford J, Watkins C, Bennett K, Gabbay M (2021) COVID-19-related social support service closures and mental well-being in older adults and those affected by dementia: a UK longitudinal survey. BMJ Open 11, e045889.

23. Losada A, Vara-Garcia C, Romero-Moreno R, Barrera-Caballero S, Pedroso-Chaparro MDS, JimenezGonzalo L, Fernandes-Pires J, Cabrera I, Gallego-Alberto L, Huertas-Domingo C, Merida-Herrera L, Olazaran-Rodriguez J, Marquez-Gonzalez M (2022) Caring for relatives with dementia in times of COVID-19: impact on caregivers and care-recipients. Clin Gerontol 45, 71-85.

24. Tsapanou A, Papatriantafyllou JD, Yiannopoulou K, Sali D, Kalligerou F, Ntanasi E, Zoi P, Margioti E, Kamtsadeli V, Hatzopoulou M, Koustimpi M, Zagka A, Papageorgiou SG, Sakka P (2021) The impact of COVID-19 pandemic on people with mild cognitive impairment/dementia and on their caregivers. Int J Geriatr Psychiatry 36, 583-587.

25. Borges-Machado F, Barros D, Ribeiro O, Carvalho J (2020) The effects of COVID-19 home confinement in dementia care: physical and cognitive decline, severe neuropsychiatric symptoms and increased caregiving burden. Am J Alzheimers Dis Other Demen 35, 1533317520976720.

26. Lara B, Carnes A, Dakterzada F, Benitez I, Pinol-Ripoll G (2020) Neuropsychiatric symptoms and quality of life in Spanish patients with Alzheimer's disease during the COVID-19 lockdown. Eur J Neurol 27, 1744-1747.

27. Carbone E, Palumbo R, Di Domenico A, Vettor S, Pavan G, Borella E (2021) Caring for people with dementia under COVID-19 restrictions: a pilot study on family caregivers. Front Aging Neurosci 13, 652833.

28. Moretti R, Caruso P, Giuffre M, Tiribelli C (2021) COVID-19 lockdown effect on not institutionalized patients with dementia and caregivers. Healthcare 9. 
29. Clare L, Nelis SM, Quinn C, Martyr A, Henderson C, Hindle JV, Jones IR, Jones RW, Knapp M, Kopelman MD, Morris RG, Pickett JA, Rusted JM, Savitch NM, Thom JM, Victor CR (2014) Improving the experience of dementia and enhancing active life-living well with dementia: study protocol for the IDEAL study. Health Qual Life Outcomes 12, 164.

30. Silarova B, Nelis SM, Ashworth RM, Ballard C, Bienkiewicz M, Henderson C, Hillman A, Hindle JV, Hughes JC, Lamont RA, Litherland R, Jones IR, Jones RW, Knapp M, Kotting P, Martyr A, Matthews FE, Morris RG, Quinn C, Regan J, Rusted JM, van den Heuvel EA, Victor CR, Wu YT, Clare L (2018) Protocol for the IDEAL-2 longitudinal study: following the experiences of people with dementia and their primary carers to understand what contributes to living well with dementia and enhances active life. BMC Public Health 18, 1214.

31. Bech P (2004) Measuring the dimension of psychological general well-being by the WHO-5. Quality of Life Newsletter 32, 15-16.

32. Skevington SM, Lotfy M, O'Connell KA, Group W (2004) The World Health Organization's WHOQOLBREF quality of life assessment: psychometric properties and results of the international field trial. A report from the WHOQOL group. Qual Life Res 13, 299-310.

33. Robertson S, Zarit S, Duncan L, Rovine M, Femia E (2007) Family caregivers' patterns of positive and negative affect. Family Relations 56, 12-23.

34. Pearlin LI, Mullan JT, Semple SJ, Skaff MM (1990) Caregiving and the stress process: an overview of concepts and their measures. Gerontologist 30, 583-594.

35. Suarez-Gonzalez A, Rajagopalan J, Livingston G, Alladi S (2021) The effect of COVID-19 isolation measures on the cognition and mental health of people living with dementia: A rapid systematic review of one year of quantitative evidence. EClinicalMedicine 39, 101047.

36. Greenberg NE, Wallick A, Brown LM (2020) Impact of COVID-19 pandemic restrictions on communitydwelling caregivers and persons with dementia. Psychol Trauma 12, S220-S221.

37. Alzheimer's Society (2020) The impact of COVID-19 on people affected by dementia.

38. Maggio MG, La Rosa G, Calatozzo P, Andaloro A, Foti Cuzzola M, Cannavo A, Militi D, Manuli A, Oddo V, Pioggia G, Calabro RS (2021) How COVID-19 has affected caregivers' burden of patients with dementia: an exploratory study focusing on coping strategies and quality of life during the lockdown. $\mathrm{J}$ Clin Med 10.

39. O'Rourke G, Pentecost C, van den Heuvel E, Victor C, Quinn C, Hillman A, Litherland R, Clare L (2021) Living with dementia under COVID-19 restrictions: coping and support needs among people with dementia and carers from the IDEAL cohort. Ageing and Society.

40. Tulloch K, McCaul T, Scott TL (2022) Positive aspects of dementia caregiving during the COVID-19 pandemic. Clin Gerontol 45, 86-96.

\section{Figures}




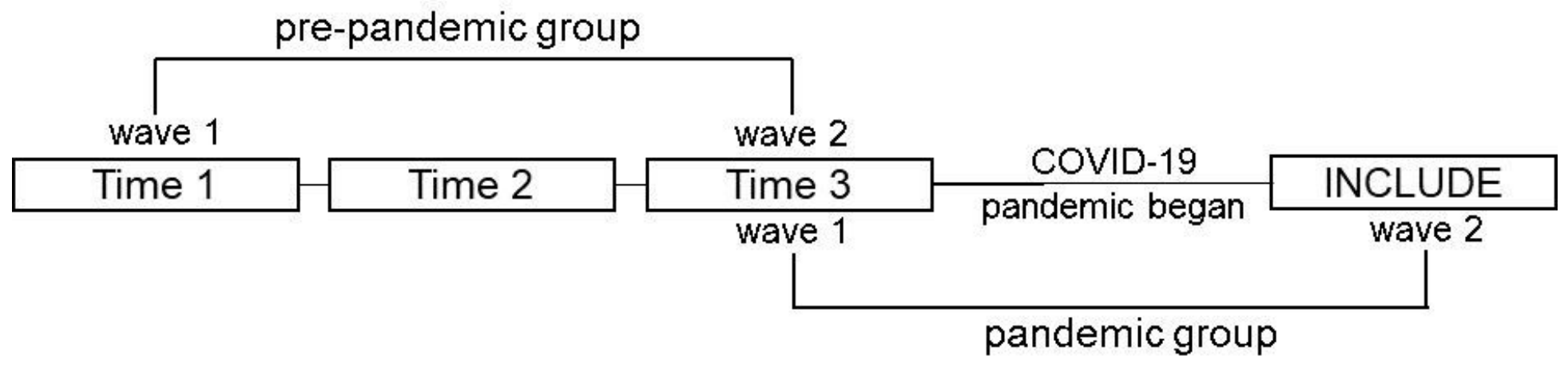

Figure 1

The timeline within the IDEAL programme defining the pre-pandemic and pandemic groups
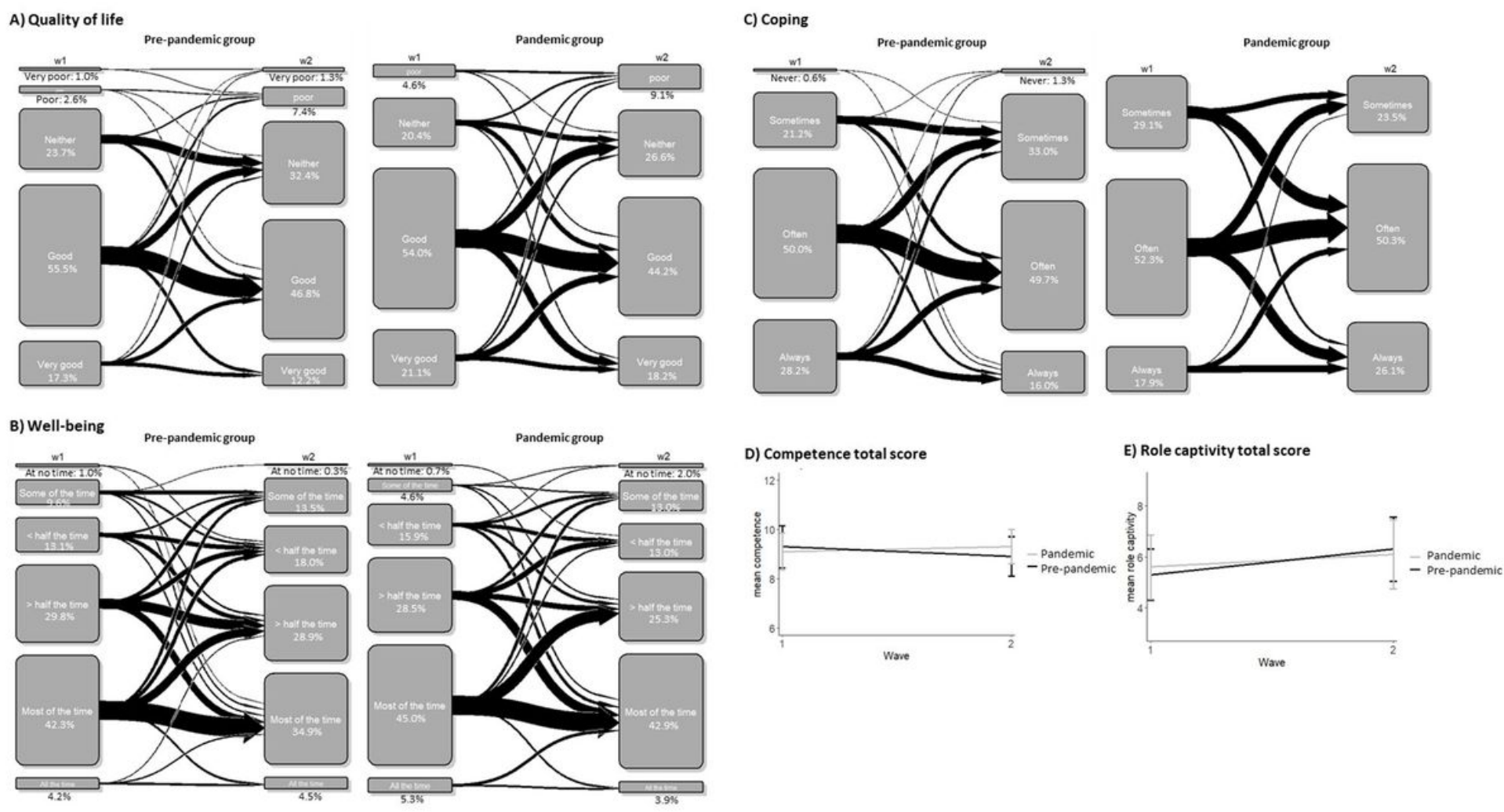

Figure 2

Transition plots of quality of life, well-being, and coping. D-E: Plots for competence and role captivity total scores

\section{Supplementary Files}

This is a list of supplementary files associated with this preprint. Click to download.

- PreprintSupplementaryMaterials.docx 